\title{
Editorial: Transition From Deficit-Irrigated to Dryland Crop Production
}

\author{
Robert J. Lascano* \\ Wind Erosion and Water Conservation Research Unit, Agricultural Research Service, United States Department of \\ Agriculture, Lubbock, TX, United States
}

Keywords: dryland, semi-arid, deficit-irrigation, cropping system, sustainability

\section{Editorial on the Research Topic}

\section{Transition From Deficit-Irrigated to Dryland Crop Production}

The Texas High Plains (THP) covers an area of $\sim 3.25$ million ha of different soil types which is subject to different rainfall resulting in several cropping systems. In this semi-arid region, rain decreases from east to west with an annual average long-term rainfall of $<500 \mathrm{~mm}$. There are three main soil series (Olton, Pullman, and Amarillo) and soils tend to be sandier in the south with finer-textured soils more common in the north. The topography is relatively flat with an average elevation of $1.1 \mathrm{~km}$ and hence the name High Plains. The combination of different soils and rain patterns results in diverse production systems. The northern region is mainly a grain-based system with wheat, corn, and grain sorghum as the main crops and in the southern region, cotton is the main crop. Given the semi-arid climate where the average annual potential evapotranspiration is $>2,400 \mathrm{~mm}$ with highly variable monthly and annual rainfall, irrigated agriculture was introduced and adopted. Large-scale irrigation started in the 1920's and was an established practice by the end of the 1930's due to the development of the internal combustion engine for pumping ground water. The source of nearly all the irrigation-water is the Ogallala aquifer, which covers eight states across the US. However, in this region, the aquifer is predominantly a closed system where extractions exceed recharge and thus over the years the water table has declined to the point that producers adopted deficit-irrigation strategies. Deficit-irrigation practices deliver less water than that required by the crop for maximum yield. As the water table continues to decline and water pumping costs rise, producers come to the realization that dryland production is the best economic option, while also conserving the remaining irrigation-water. No irrigation leads to dryland production systems, which we define as crop production without irrigation and with $<500 \mathrm{~mm}$ of annual rainfall in a semi-arid climate. This is the backdrop of the series of papers that address the transition from deficit-irrigated to dryland crop production in the THP.

Agricultural production in the THP is in a unique position in that the transition from deficitirrigation to dryland production has been gradual. This has provided valuable time for research scientists to address and develop economically viable dryland production systems. Agriculture production in this dryland region is challenged by frequent droughts and high climatic variability that can lead to land degradation and threaten the agricultural sustainability of the region. Further, the environmental complexity of dryland crop production requires an integrated and multidisciplinary research approach to address the uncertainty associated with rainfall variability. To this end, in this collection of six papers, agronomists, soil scientists, plant physiologists and breeders, agricultural engineers, climatologist, and economists have come together to answer questions concerning management practices that could increase crop yields and minimize production risks. A common denominator in four of the six papers is the use of models, i.e., crop and economic, to 
evaluate how a management practice such as seeding rate affects dryland crop yield over multiple years and locations. Simulation models are powerful tools and the results they provide are essential to develop best management practices for producers in this region.

Problems associated with dryland agriculture can be formulated and addressed with simulation models. However, these simulated solutions are site-specific and results obtained with a model must be verified with measured data gathered from field experiments. In practice, simulation models can be used to identify knowledge gaps and to design specific experiments to test hypotheses. Field experiments conducted over many years and sites are expensive and these data sets provide an invaluable resource that can be used to test models. For example, the effect of tillage and slope on measured runoff in a 3 year rotation of wheat-sorghum-fallow on crop yield since 1983 in Bushland, TX is an example of a valuable data set. This is a unique data-set that provides results that do not require a simulation model to provide recommendations. Further, this data set can be used in conjunction with a simulation model to extrapolate these results to other locations. A word of caution is that skepticism must be exercised with the results generated from models. There is no substitute for measured data particularly when it covers multiple years and is from landscape-scale field plots.

In the two papers by Mauget, Marek, et al. and Mauget, Kothari, et al. the CROPCRO-Cotton model was used to optimize management options for dryland cotton and the DSSAT-CSM model that uses the CERES-Sorghum growth module was used for dryland sorghum production in the THP. For both crops, the model was used to evaluate 32 management options consisting of 4 planting dates and 4 planting densities, and application vs. no application of nitrogen fertilizer $(4 \times 4 \times 2=32$ management options). The models were applied to 21 locations across the THP and for an 11-year period. The management option that produced the highest median cotton lint yield was the earliest planting date, at the lowest planting density and with no nitrogen fertilizer application. Lint yield values from ongoing field trials support this management option as well as economic profitability given the high cost of cotton-seed and nitrogen fertilizer. The highest median grain sorghum yield was obtained with the latest planting date and lowest plant density with no effect due to nitrogen. This result is somewhat unexpected given the rainfall pattern of the THP and illustrates how a model can be used to design field experiments to test a simulated value.

In the paper by Baumhardt, Marek et al. the capture of precipitation and its loss to runoff from a wheat-sorghumfallow rotation was evaluated for a 20-year data set collected in Bushland, TX. These results indicated that rain storms of $>50 \mathrm{~mm}$ produced water runoff. This runoff was found to be greater in no-till plots compared to stubble-mulched plots. This work also attempted to correlate the number of precipitation events during the El Niño-Southern Oscillation (ENSO) warm phase with number of precipitation events during the La Niña cold phase. During El Niño phase, the number of precipitation events during the months of December through February tended to be higher than normal. During La Niña phase, the number of precipitation events during the months of November through January, respectively, tended to be lower than normal. These results support the recommendation of no till to reduce runoff and capture more water to store in the soil and support the use of forecasts of El Niño and La Niña phases for dryland production of summer crops in the THP. In their second paper, Baumhardt, Dockal et al. again used a long-term data set beginning in 1983, where runoff was measured from farmed fields managed in a wheat-sorghum-fallow rotation with either no-tillage or stubblemulch tillage. These results indicated more runoff during fallow period for the no-till, while wheat grain yield did not respond to tillage treatment. The overall conclusion was that management of tillage was important in order to decrease runoff from rainfall thus capturing more water to store in the soil.

Ale et al. used the CROPGRO-cotton simulation model with DSSAT, a decision support system, to evaluate the effects of drainage, surface runoff, soil water holding capacity, albedo, and soil organic carbon for dryland cotton in the THP over a period of 15 years. Results were as expected, i.e., increasing the soil water holding capacity, decreasing runoff, increasing albedo and drainage all resulted in an increase in the simulated seedcotton yield. However, changes in the soil organic carbon did not significantly affect the simulated seed-cotton yield. Further, a risk and economic analysis from simulating these different scenarios indicated that proper management of these factors could help reduce revenue risk for dryland cotton producers across the THP. A final paper in the series, by Mitchell-McCallister et al. focused on an economic analysis of the transition from deficit-irrigated to dryland production. They applied a non-linear optimization model to estimate optimal water use, crop species, and cultivar mix and final crop yield, and net economic returns for a 50year period under dryland and deficit-irrigation scenarios in the THP. The main result from these simulations is that producers in the THP could maintain profitability by converting fully irrigated center pivots to $50-75 \%$ dryland production. This practice would further extend the longevity of the Ogallala aquifer while maintaining a profitable farm enterprise. This indeed is an encouraging conclusion for the future sustainability and profitability of the dryland agriculture in the THP. The capture of precipitation as soil water in the profile is key for a successful dryland crop production system.

\section{AUTHOR CONTRIBUTIONS}

The author confirms being the sole contributor of this work and has approved it for publication.

Conflict of Interest: The author declares that the research was conducted in the absence of any commercial or financial relationships that could be construed as a potential conflict of interest.

Copyright (C) 2021 Lascano. This is an open-access article distributed under the terms of the Creative Commons Attribution License (CC BY). The use, distribution or reproduction in other forums is permitted, provided the original author(s) and the copyright owner(s) are credited and that the original publication in this journal is cited, in accordance with accepted academic practice. No use, distribution or reproduction is permitted which does not comply with these terms. 